ISSN № 9125 0912. ВІСНИК ДНУ. Серія «Mameмamuка». № 6/1. 2011. Bun. 16.

\title{
УДК 512.544
}

\author{
О.О. Пипка
}

Дніпропетровський науіональний університет імені Олеся Гончара

\section{БУДОВА СКІНЧЕННИХ ГРУП, В ЯКИХ КОЖНА ПРОНОРМАЛЬНА ПЦДРУПА АБО НОРМАЛЬНА, АБО АБНОРМАЛЬНА}

Підгрупа $H$ групи $G$ називасться абнормальною в $G$, якшо $g \in<H, H^{k}>$ для довільного елементу $g \in G$. Підгрупа $H$ групи $G$ називається пронормальною в $G$, якшо для довільного $g \in G$ підгрупи $H$ i $H^{g}$ спряжені у породженій ними групі $<H, H^{*}>$. Описані всі скінченні групи, кожна пронормальна підгрупа яких або нормальна, або абнормальна.

Ключові слова: аб̆номальна підгрупа, пронормальна підгрупа.

Подгруппа $H$ группы $G$ называется абнормальной в $G$, если $g \in\left\langle H, H^{*}\right\rangle$ для произвольного элемента $g \in G$. Подгруппа $H$ группы $G$ называетея пронормальной в $G$, если для произвольного $g \in G$ подгруппь $H$ и $H^{g}$ сопряжены в порожденной ими группе $<H, H^{g}>$. Описаны все конечные группы, каждая пронормальная подгруппа которых либо нормальна, либо абнормальна.

Ключевые слова: абнормальная подгруппа, пронормальная подгруппа.

A subgroup $H$ of a group $G$ is said to be abnormal in $G$ if for each element $g \in G$ we have $g \in<H, H^{z}>$. A subgroup $H$ of a group $G$ is said to be pronormal in $G$ if for each element $g \in G$ the subgroups $H$ and $H^{g}$ are conjugate in $<H, H^{g}>$. We describe all finite groups, each pronormal subgroups are either normal or abnormal.

Key words: abnormal subgroup, pronormal subgroup.

Підгрупа $H$ групи $G$ називається абнормальною в $G$, якщо для довільного елементу $g \in G$ виконуеться умова $g \in<H, H^{g}>$. Цей тип підгруп був введений Ф. Холлом в [4], проте сам термін «абнормальна підгрупа» належить Р. Картеру [3]. Абнормальні підгрупи $\epsilon$ антиподами нормальних підгруп та іх узагальнень (одночасно підгрупа може бути нормальною та абнормальною лише в тому випадку, коли вона співпадає з усією групою). Так, наприклад, абнормальна підгрупа $є$ самонормалізуємою $\left(N_{G}(H)=H\right)$, та контранормальною, тобто $H^{(i}=G$. Підгрупи такого типу відіграють достатньо серйозну роль в теорії скінченних груп. Одним 3 узагальнень аб̆ормальних підгруп є пронормальні підгрупи. Підгрупа $H$ групи $G$ називається пронормальною в $G$, якщо підгрупи $H$ і $H^{g}$ спряжені в групі $\left\langle H, H^{\prime}\right\rangle$ для довільного елементу $g \in G$. Інакше кажучи, $H^{g}=H^{x}$ для деякого елементу $x \in<H, H^{g}>$. Цей тип підгруп був також введений Ф. Холлом. Важливими прикладами пронормальних підгруп є силовські $p$-підгрупи скінченних груп, силовські $\pi$-підгрупи та картерові підгрупи скінченних розв'язних груп та ін. На відміну від абнормальних підгруп, пронормальні підгрупи можуть бути нормальними. Тому можна говорити, що нормальні та абнормальні підгрупи

O.О. Пипка, 2011 
розташовані на двох протилежних кінцях сімейства всіх пронормальних підгруп. У зв'язку з цим виникає питання про будову груп, кожна пронормальна підгрупа яких $\epsilon$ або нормальною, або абнормальною. Виявилось, що в деяких скінченних лінійних групах кількість пронормальних підгруп, що $€$ нормальними або абнормальними, у порівнянні із загальною кількістю пронормальних підгруп, є досить невеликою [2]. Це наштовхує нас на думку, що можна отримати повний опис таких груп. Результат цієї роботи показує, що так i $\epsilon$.

У даній роботі знайдена будова всіх скінченних груп, кожна пронормальна підгрупа яких або нормальна, або аб̆нормальна.

Лема 1. Нехай $G$ - група, в якій кожна пронормальна підгрупа $\epsilon$ або нормальною, або абнормальною. Нехай $H \triangleleft G$, тоді у фактор-групі $G / H$ кожна пронормальна підгрупа також буде або нормальною, або абнормальною.

Доведення. Нехай $K$ - пронормальна підгрупа групи $G$. Тоді або $K \triangleleft G$, або $K$ абнормальна в $G$. Нехай $H \triangleleft G, H \leq K$. Візьмемо довільний елемент $g h \in G / H$ і розглянемо підгрупу $K / H$ фактор-групи $G / H$.

$$
(K / H)^{g h}=K^{g h} / H=K^{g} / H=K^{x} / H=K^{x h} / H=(K / H)^{x h},
$$

для деякого елементу $x h$ такого, що

$$
x h \in<K / H,(K / H)^{g h}>=<K / H, K^{g} / H>=<K, K^{g}>/ H .
$$

Отже, якщо $K$ - пронормальна підгрупа групи $G, H \triangleleft G, H \leq K$, тоді $K / H$. буде пронормальною підгрупою фактор-групи $G / H$.

Як відомо, $K / H \triangleleft G / H$ тоді і тільки тоді, коли $K \triangleleft G$. Припустимо тепер, що $K$ - абнормальна підгрупа групи $G$. Розглянемо наступну групу

$$
<K / H,(K / H)^{g h}>=<K / H, K^{g} / H>=<K, K^{g}>/ H .
$$

Очевидно, що остання група містить у собі елемент $g h$. Таким чином,

$$
g h \in<K / H,(K / H)^{g h}>
$$

для довільного елементу $g h \in G / H$. А це означає, що $K / H$ абнормальна в $G / H$. Лему доведено.

Лема 2. Нехай $G$ - скінченна група, в якій кожна пронормальна підгрупа є або нормальною, або абнормальною. Тоді $G$ розв'язна.

Доведення. Припустимо, що $G$ не е розв'язною. Візьмемо в групі $G$ максимальну нормальну розв'язну підгрупу $S$. Розглянемо силовську $p$-підгрупу $H_{p} / S$ фактор-групи $G / S$, тоді $H_{p} / S$ пронормальна в $G / S$, і за лемою $1 H_{p} / S$ або нормальна, або абнормальна підгрупа $G / S$. Припустимо, що $H_{p} / S \triangleleft G / S$. Довільна $p$-група розв'язна при будь-якому простому $p$. Отже, $H_{p}$ - це розширення розв'язної групи. за допомогою розв'язної. Воно також розв'язне. Таким чином, $H_{p}$ - це розширення максимальної нормальної розв'язної підгрупи $S$, при цьому $H_{p} \triangleleft G$. А це суперечить вибору підгрупи $S$. 
3 цього випливає, що $H_{p} / S * G / S$, а тому $H_{p} / S$-абнормальна в $G / S$. Будьяка абнормальна підгрупа самонормалізуєма, тоді

$$
N_{G / S}\left(H_{p} / S\right)=H_{p} / S \text {. }
$$

Зокрема, підгрупа $N_{G / S}\left(H_{p} / S\right)$ є $p$-нільпотентною (нагадаємо, що група $G$ називасться $p$-нільпотентною, якщо ії силовська $p$-підгрупа нормальна в $G$ ). За теоремою 2 [1] фактор-група $G / S$ нільпотентна, а оскільки $S$ максимальна підгрупа групи $G$, то $G$ - розв'язна, що суперечить нашому припущенню. Лему доведено.

Лема 3. Нехай $G$ - скінченна група, в якій кожна пронормальна підгрупа $\epsilon$ або нормальною, або абнормальною. Якщо $H$ - власна нормальна підгрупа групи $G$ і $H$ містить у собі підгрупу $K$, яка пронормальна в $G$, то $K$ нормальна в $G$.

Доведення. Нехай $H$ - власна нормальна підгрупа групи $G$ і $K$ пронормальна підгрупа групи $G, K \leq H$. Будь-яка абнормальна підгрупа $\epsilon$ контранормальною, тобто ії нормальне замикання співпадає з усією групою. Оскільки $K \leq H$, то $K^{G} \leq H^{G}$. $H$ нормальна в $G$, тому $H^{G}=H$. Отже, ми отримали, що

$$
K^{G} \leq H \neq G
$$

а тому $K$ не може бути абнормальною. Таким чином, $K$ нормальна в $G$. Лему доведено.

Наслідок. Нехай $G$ - скінченна група, в якій кожна пронормальна підгрупа є або нормальною, або абнормальною. Якщо $H$ - власна нормальна підгрупа групи $G$, то всі силовські підгрупи $H$ нормальні в $G$.

Доведення. Беручи до уваги те, що будь-яка силовська підгрупа пронормальна, то за лемою 3 всі силовські підгрупи групи $H$ нормальні в $G$.

Теорема. Нехай $G$ - скінченна група, в якій кожна пронормальна підгрупа є або нормальною, або абнормальною. Тоді або $G$ нільпотентна, або задовольняє наступні умови:

- $G=Q \diamond P, Q-$ - нільпотентна підгрупа, $P$ - силовська р-підгрупа групи $G$;

- $P=B\langle x\rangle, x^{p} \in B$

- $C_{G}(Q)=B$;

- $C_{Q}(x)=<1>$.

Доведення. За лемою 2 група $G$ - розв'язна, зокрема, вона містить у собі таку максимальну нормальну підгрупу $H$, що

$$
|G: H|=p
$$

де $p$ - просте. $G / H$ - циклічна група і породжується будь-яким своїм елементом $x H$ ( $x$ можемо вибрати таким чином, щоб він був $p$-елементом), a отже

$$
G=H\langle x\rangle,
$$

де $x^{p} \in H$. 


\section{O.O. ППИПKA}

Оскільки $H$ - нільпотентна, то вона $є$ прямим добутком своїх силовских підгруп:

$$
H=Q \times B,
$$

де $B$ - силовська $p$-підгрупа, а $Q$ - силовська $p^{\prime}$-підгрупа. Беручи до уваги той факт, що $|G: H|=p$, то $Q$ буде силовською $p^{\prime}$-підгрупою для всієї групи $G$, а $P=B\langle x\rangle-$ силовською $p$-підгрупою групи $G .3$ рівностей $G=H\langle x\rangle$ та $H=Q \times B$ отримуємо, що $G=Q P$, а оскільки $Q \cap P=<1>$, то

$$
G=Q \lambda P \text {. }
$$

$P$ пронормальна в $G$. Якщо $P \triangleleft G$, то $G$ - нільпотентна. Нехай $P * G$. Припустимо, що $C_{Q}(x) \neq<1>$. Тоді існує хоча $б$ один елемент $y \in Q$, який переставний з $x$. Очевидно, що $|y|$ не ділиться на $p$. Оскільки

$$
C_{Q}(x) \leq C_{G_{j}}(P) \triangleleft N_{G j}(P),
$$

то $y \in N_{G}(P)$, проте $y \notin P$. Отже $N_{G}(P) \neq P$, але ж $P$ абнормальна, а тому самонормалізуєма. Отримане протиріччя показує, що

$$
C_{H,}(x)=<1>\text {. }
$$

Теорему доведено.

\section{Бібліографічні посилання}

1. Баллестер-Болинше А. О нормализаторах силовских подгрупп в. конечных группах/ А. Баллестер-Болинше, Л.А. Шеметков // Сибирский математический журнал. 1999 , T. 40, №1. - С. 3-5.

2. Пипка О.О. Про деякі типи антинормальних підруп / О.О. Пипка, В.А. Чупордя // Вісник Дніпропетр. ун-ту. Математика. 2010, Вип. 15. - С. 141-144.

3. Carter R.W. Nilpotent self-normalizing subgroups of soluble groups. / R.W. Carter // Math. Z. - 1961 - No 75 - P. 136-139.

4. Hall P. On system normalizers of soluble groups. / P, Hall // Proc. London Math. Soc. 1937. - № 43. - P. 507-528.

Hadiйuла do pedколезіi 23.03.11 